\title{
Diagnostic value of risk malignancy index (RMI) for detection of malignancies in clinically diagnosed ovarian masses and to evaluate the validity of individual constituent parameter of risk malignancy index
}

\author{
Jenitha B. ${ }^{1 *}$, Subbiah M. ${ }^{2}$
}

\begin{abstract}
${ }^{1}$ Department of Obstetrics and Gynecology, ${ }^{2}$ Department of Pediatrics, Trichy SRM Medical College and Research Centre, Trichy, Tamil Nadu, India
\end{abstract}

Received: 21 January 2019

Accepted: 05 March 2019

\author{
*Correspondence: \\ Dr. Jenitha B., \\ E-mail: drbjenitha@gmail.com
}

Copyright: (c) the author(s), publisher and licensee Medip Academy. This is an open-access article distributed under the terms of the Creative Commons Attribution Non-Commercial License, which permits unrestricted non-commercial use, distribution, and reproduction in any medium, provided the original work is properly cited.

\begin{abstract}
Background: Pre-operative knowledge regarding the nature of ovarian mass is necessary in order to plan surgery. Risk malignancy index (RMI) is a simple scoring system based on three factors serum CA 125, USG score and menopausal status. The RMI was interpreted as 1) score $>250=$ high risk, 2) $25-250=$ intermediate risk, 3) score $<25=$ low risk. The objective of the study was to evaluate risk malignancy index (RMI) in pre-operatively clinically diagnosed ovarian mass and to compare the validity of individual parameter in RMI i.e. menopausal status, serum CA 125 and USG score to differentiate the nature of clinically diagnosed ovarian masses as benign or malignant.

Methods: This was an observational study conducted in the Department of obstetrics and gynaecology, Trichy SRM Medical College and Research Centre, Trichy from January 2017 to January 2018 with a sample size of 77 cases with clinical diagnosis of ovarian mass admitted for surgery. The validity of RMI and validity of individual parameters were calculated and compared.

Results: A total of 77 patients with ovarian tumors were enrolled in this study. According to the histological examination of the surgical specimens of the 77 women, $27.3 \%(n=21)$ had malignant tumors and $67.7 \%(n=56)$ had benign disease. Most common benign tumour was serous cystadenoma and the most common malignant tumour was mucinous cystadenocarcinoma. Among 77 patients, $42.85 \%(n=33)$ were postmenopausal, 44.15\% ( $n=34)$ had USG score of 4, 27.27\% $(n=21)$ had serum CA125 level >cut-off values and 27.27\% $(n=21)$ had RMI $>250$. In cases where RMI $>250,18$ out of 21 were malignant. In cases where USG score was 4, 19 out of 34 were malignant. Of the cases where serum CA125 level was > cut-off values 16 out of 21 were found to be malignant. RMI showed better sensitivity of $85.71 \%$, specificity of $94.64 \%$, PPV of $85.71 \%$, NPV of $94.64 \%$ and diagnostic accuracy of $92.20 \%$.

Conclusions: RMI is highly valuable and reliable in differentiating benign and malignant ovarian lesions and facilitates selection of cases for conservative management and oncology referral.
\end{abstract}

Keywords: Benign, CA125, Malignant, Oncology, RMI, USG

\section{INTRODUCTION}

Up to $24 \%$ of ovarian tumors in premenopausal women are malignant and up to $60 \%$ are malignant in postmenopausal women. ${ }^{1-3}$ The preoperative diagnosis of whether a mass is malignant cannot always be made with current diagnostic modalities. Surgery can be optimally planned if an ovarian neoplasm is known to be benign or malignant in advance. There is a significant difference in management of a malignant tumour which may require 
radical surgery, chemotherapy, counselling regarding the disease prognosis and costs involved. On the other hand benign adnexal mass may simply be managed with cystectomy or ovariotomy. This is adequate to signify the importance of pre-operative determination of the nature of adnexal mass for optimal and appropriate primary treatment.

The scoring methods based on menopausal status, ultrasonographic examination and serum CA-125 yield much better results than the earlier mentioned individual parameters. $^{4-6}$ Risk of Malignancy Index (RMI) is calculated with a simplified regression equation obtained from the product of menopausal status score (M), ultrasonographic score (U) and absolute value of serum CA-125. This scoring system helps in differentiating benign from malignant masses. In many studies, cut off value of Risk of malignancy index was taken as 200 but according to RCOG guidelines, the cut off level is 250 for predicting malignancy since higher cut off level increased the detection rate of true negative cases. ${ }^{7-9}$

This study was aimed to assess the validity of RMI in clinically diagnosed ovarian masses in preoperative women and comparing it with the validity of individual constituent parameter of RMI.

\section{METHODS}

This was an observational study conducted in the Department of Obstetrics and Gynaecology, Trichy SRM Medical College and Research Centre, Trichy from January 2017 to January 2018 with a sample size of 77 cases with clinical diagnosis of ovarian mass admitted for surgery. The validity of RMI and validity of individual parameters were calculated and compared.

\section{Inclusion criteria}

- Women with clinically restricted ovarian mass of any age group.

- For premenopausal women, criteria for ovarian masses are its size more than $8 \mathrm{~cm}$ and for postmenopausal women size more than $5 \mathrm{~cm}$.

- Post-menopausal status defined as more than 1 year of amenorrhea or women who underwent hysterectomy.

\section{Exclusion criteria}

- Patients who were unfit for major surgery and inoperable cases.

- Any other intraoperative mass other than ovarian mass were excluded.

Total 77 women with clinically diagnosed as ovarian mass who were admitted for surgery after fulfilling the inclusion and exclusion criteria were studied. Detailed clinical history was taken. Clinical examination was done. USG (abdomen+pelvis) performed with full bladder.

\section{Ultrasound scoring}

Ultrasound score (U) was based on one point for each of the following:

1. Bilateral lesion

2. Multilocular cyst with septations

3. Evidence of solid areas

4. Evidence of metastasis

5. Presence of ascites

For RMI USG score,

$\mathrm{U}=1$ for ultrasound point of 0 or 1

$\mathrm{U}=4$ for ultrasound point of $>1$

Ultrasound scoring were recent ones done within two weeks prior to laparotomy.

\section{Serum CA-125 level estimation}

Peripheral venous blood sample $(5 \mathrm{ml})$ was drawn from each patient, prior to surgery for the estimation of serum CA-125. Serum CA $125>200 \mathrm{IU} / \mathrm{ml}$ in premenopausal and $>35 \mathrm{IU} / \mathrm{ml}$ in postmenopausal women were considered together as high risk of ovarian malignancy.

\section{Menopausal scoring (M)}

For premenopausal woman score 1 was given, for postmenopausal woman score 4 was given. RMI calculated for each subject by multiplying USG score, Menopausal score and Serum CA125 level value.

RMI 2 $=\mathrm{U} \times \mathrm{M} \times$ Serum CA-125 level. ${ }^{10}$

Operative findings during laparotomy of all cases were obtained. It was made sure that the operated specimen or tissue was immersed in formalin solution and sent for histopathological examination. Ascitic fluid or peritoneal washing was sent for cytological examination in a sterile syringe immediately. The cytological and histopathological examinations were all done in the Department of Pathology. Histopathological diagnosis was considered as gold standard for defining outcome.

\section{Interpretation of risk malignancy index (RMI)}

If the score was $<25$, it was considered as low risk. If the score was 25-250, it was considered as moderate risk and if the score was $>250$, it was considered as high risk.

\section{Statistical analysis}

Statistical analysis was done with appropriate test at the end of the study. 
Results of RMI were validated against histopathologically confirmed lesions.

\section{RESULTS}

A total of 77 patients with ovarian tumors were enrolled in this study, of which, based on histopathological examination of the surgical specimen reports, 56 patients $(72.7 \%)$ had benign tumors and 21 patients $(27.3 \%)$ had malignant lesions.

Table 1: Distribution of cases based on histopathology.

\begin{tabular}{|l|l|}
\hline Histopathologic diagnosis & $\begin{array}{l}\text { Benign cases } \\
(\mathbf{N}=\mathbf{5 6})\end{array}$ \\
\hline Serous cystadenoma & 28 \\
\hline Dermoid cyst & 7 \\
\hline Endometriotic cyst & 6 \\
\hline Mucinous cystadenoma & 5 \\
\hline Serous cystadenofibroma & 5 \\
\hline Corpus luteal cyst & 2 \\
\hline Fibrothecoma & 1 \\
\hline Ovarian abcess & 1 \\
\hline Sertoli leydig cell tumour & 1 \\
\hline & $\mathbf{M a l i g n a n t}$ cases \\
\hline Mucinous cystadenocarcinoma & $\mathbf{( N = 2 1 )}$ \\
\hline Serous cystadeno carcinoma & 5 \\
\hline Clear cell adenocarcinoma & 2 \\
\hline Krukenberg Tumour & 2 \\
\hline Mixed germ cell tumour & 1 \\
\hline Dysgerminoma & 1 \\
\hline Endometroid adenocarcinoma & 1 \\
\hline
\end{tabular}

Table 2: Distribution of cases based on USG score, CA125 levels, menopausal status and RMI.

\begin{tabular}{|l|l|l|}
\hline Variable & $\begin{array}{l}\text { Total number } \\
\text { of cases }\end{array}$ & $\begin{array}{c}\text { Percentage of } \\
\text { ovarian mass }\end{array}$ \\
\hline Menopausal status & \multicolumn{2}{|c|}{} \\
\hline $\begin{array}{l}\text { Premenopausal } \\
\text { Postmenopausal }\end{array}$ & 44 & 57.14 \\
\hline USG score & 33 & 42.85 \\
\hline 1 & 43 & 55.84 \\
\hline 4 & 34 & 44.15 \\
\hline Serum CA & & \\
\hline$>$ Cut-off & 21 & 27.27 \\
\hline$<$ Cut-off & 56 & 72.72 \\
\hline RMI score & & \\
\hline$<25$ & 14 & 18.18 \\
\hline $25-250$ & 42 & 54.55 \\
\hline$>250$ & 21 & 27.27 \\
\hline
\end{tabular}

The common benign tumors were serous cystadenoma $(n=28)$, dermoid cyst $(n=7)$, endometriotic cyst $(n=6)$, mucinous cystadenoma $(n=5)$, serous cystadenofibroma $(n=5)$ and corpus luteal cyst $(n=2)$, while the common malignant tumors were mucinous cystadenocarcinoma $(n=9), \quad$ serous adenocarcinoma $(n=5)$, clear cell adenocarcinoma $(\mathrm{n}=2)$ and krukenberg tumor $(\mathrm{n}=2)$ (Table 1).

Among 77 patients, 33 patients (42.85\%) were postmenopausal, 34 patients $(44.15 \%)$ had USG score of 4, 21 patients $(27.27 \%$ ) had serum CA125 level >cut-off values and 21 patients $(27.27 \%$ ) had RMI > 250 (Table 2 ).

Table 3: Correlation of RMI and its individual parameters with histopathology.

\begin{tabular}{|c|c|c|c|}
\hline Variable & $\begin{array}{l}\text { Benign } \\
(\mathrm{N}=56)\end{array}$ & $\begin{array}{l}\text { Malignant } \\
(\mathrm{N}=21)\end{array}$ & $\begin{array}{r}\text { Total } \\
(\mathrm{N}=77)\end{array}$ \\
\hline \multicolumn{4}{|c|}{ Menopausal status } \\
\hline Premenopause & $37(84 \%)$ & $7(16 \%)$ & 44 \\
\hline Postmenopause & $19(57.6 \%)$ & $14(42.4 \%)$ & 33 \\
\hline \multicolumn{4}{|l|}{ USG score } \\
\hline 1 & $41(95.3 \%)$ & $2(4.7 \%)$ & 43 \\
\hline 4 & $15(44.1 \%)$ & $19(55.9 \%)$ & 34 \\
\hline \multicolumn{4}{|c|}{ Serum CA125 level } \\
\hline$<$ Cut-off & $51(91.1 \%)$ & $5(8.9 \%)$ & 56 \\
\hline$>$ Cut-off & $5(23.8 \%)$ & $16(76.2 \%)$ & 21 \\
\hline \multicolumn{4}{|l|}{ RMI score } \\
\hline$>250$ & $3(14.3 \%)$ & $18(85.7 \%)$ & 21 \\
\hline$<250$ & $53(94.6 \%)$ & $3(5.4 \%)$ & 56 \\
\hline
\end{tabular}

From the 44 pre-menopausal patients involved in this study, 7 had tumors (16\%) that were malignant and 37 (84\%) had benign tumors, while with the 33 postmenopausal patients, $14(42.4 \%)$ had malignant tumors and $19(57.6 \%)$ had benign tumors. In cases where USG score was 1 , only $4.7 \%(n=2)$ patients had malignancy, whereas $55.9 \%(n=19)$ had malignancy when the USG score was 4 . Among 56 patients only $8.9 \%(n=5)$ were found to be malignant when the serum CA125 level was $<$ cut-off value, whereas $16(76.2 \%)$ out of 21 patients had malignant tumors when the serum CA level was $>$ cut-off value. In cases where RMI> 250, 18(85.7\%) out of 21 patients had malignancy, whereas only $3(5.4 \%)$ among 56 patients were found to be malignant when the RMI score was $<250$ (Table 3).

In present study sensitivity, specificity, positive predictive value (PPV) and negative predictive value (NPV) of menopausal status were $67 \%, 66 \%, 45 \%$ and $84 \%$ respectively. USG score had sensitivity of $90 \%$, specificity of $73 \%$, positive predictive value (PPV) of $56 \%$ and negative predictive value (NPV) of $95 \%$. The sensitivity, specificity, positive predictive value (PPV) and negative predictive value (NPV) of serum CA 125 level were $76 \%, 91 \%, 76 \%$ and $91 \%$ respectively. RMI score had sensitivity of $86 \%$, specificity of $95 \%$, positive predictive value (PPV) of $86 \%$ and negative predictive value (NPV) of $95 \%$. Table 4 shows that diagnostic accuracy is very high for RMI score than individual parameters. Of the individual parameters USG shows highest sensitivity and negative predictive value (Table 4). 
Table 4: Validity of RMI and its parameters in predicting the risk of malignancy in ovarian masses.

\begin{tabular}{|l|l|l|l|l|l|}
\hline Statistical parameter & Sensitivity (\%) & Specifficity (\%) & PPV (\%) & NPV (\%) & DA (\%) \\
\hline Menopausal status & 66.66 & 66.07 & 45.16 & 84.09 & 66.23 \\
\hline USG score & 90.45 & 73.21 & 55.88 & 95.35 & 77.92 \\
\hline Serum CA125 level & 76.19 & 91.07 & 76.19 & 91.07 & 87.01 \\
\hline RMI score & 85.71 & 94.64 & 85.71 & 94.64 & 92.20 \\
\hline
\end{tabular}

\section{DISCUSSION}

The present study has revealed the usefulness of RMI to correctly discriminate benign from malignant pelvic masses. In present study totally 77 patients with ovarian mass were enrolled. Among them $72.7 \%(\mathrm{n}=56)$ had benign tumors, $27.3 \%(\mathrm{n}=21)$ had malignant tumors. Most common benign tumour was serous cystadenoma and the most common malignant tumour was mucinous cystadenocarcinma. present results were comparable with Yamamoto et al, who studied 253 patients with pelvic masses (mean age for benign masses was 39 and 54 for malignant ones), where $84.2 \%(\mathrm{n}=213)$ proved to be benign and $15.8 \%(n=40)$ proved to be malignant. ${ }^{11}$ In the present study, $42.4 \%$ of malignancies occurred in postmenopausal women, whereas Tingulstad et al, reported $80 \%$ of malignancies occurred in postmenopausal women. In present study USG score had sensitivity of $90 \%$, specificity of $73 \%$, positive predictive value (PPV) of $56 \%$ and negative predictive value (NPV) of $95 \%$. present results were comparable with the study conducted by C. A. Hartman et al in which USG had a sensitivity of $90 \%$, specificity of $87 \%$, positive predictive value (PPV) of $69 \%$ and negative predictive value (NPV) of $97 \% .{ }^{12}$ Risk of malignancy index is the integration of serum CA- 125, menopausal status and USG findings. ${ }^{10}$ In the present study, the cut off level of RMI is taken as 250.This scoring was more closer to Bouzari $\mathrm{Z}$ et al who used 265 as cut off. ${ }^{13}$ In the present study, out of 77 clinically diagnosed ovarian masses, 3 cases were noted with lower RMI (i.e. <250) which turned out to be malignant on histopathology. This gave the false negative rate of $3.89 \%$. It was also noted that in these 3 cases, Serum CA 125 level was within normal range. This could be explained on the basis of histopathology of individual cases. Out of these cases, one case was dysgerminoma, one was Krukenberg tumour and one case was endometroid adenocarcinoma. Similar findings were noted by Kestane I et al. ${ }^{14}$ Immuno histochemical studies have demonstrated Serum CA-125 expression to be a feature of cells derived from embryonal coelomic epithelium and Mullerian duct. ${ }^{15}$ Serum CA-125 levels usually rise in epithelial tumors, whereas levels may not increase in non-epithelial tumor like dysgerminoma, immature teratoma, sex cord stromal tumor. In the 2012 study by Anton et al, it was concluded that there is no difference between RMI, the risk ovarian malignancy algorithm, human epididymis protein 4 levels, and CA125 levels in discriminating between different types of ovarian tumors. ${ }^{16}$ RMI had the lowest sensitivity but is the most commonly applied method. The HE4 showed the highest sensitivity for differentiation between ovarian malignancy and endometriosis. All of the parameters showed sensitivity and can be reliably used as a basis for patient referral. In this study, RMI 2 showed the best performance in predicting malignancy, compared with the other three indices. As per the study by Zarchi MK et al, in 2015, RMI 2 showed the best performance in differentiating benign from malignant ovarian masses. ${ }^{17}$

Although USG score showed increased sensitivity and negative predictive value the diagnostic accuracy is low compared to RMI. Varras believed that ultrasound examination is not an independent factor for diagnosis of malignancy and imaging should not be regarded as the sole decision-making method for surgical intervention because radiological findings show considerable overlap between benign and malignant masses. ${ }^{18}$ In present study, menopausal status had a sensitivity of $66.6 \%$ and specificity of $66.07 \%$. Hence menopausal status could be a weak constituent of RMI. Comprehensive index overcomes the false positive result obtained when using a single parameter like menopausal status or serum CA-125 or USG alone. If patients with ovarian cancers are diagnosed at early stage (I or II), the cure rate could be as high as $80-90 \%$ and the mortality rate could decrease up to $50 \%$. Hence, this method of diagnosis is of great importance for prediction of the prognosis. Selective referral of patients with high risk of malignancy to specialized oncology centres is of paramount importance. The primary cytoreductive surgery has a great role in deciding the prognosis of ovarian cancers. ${ }^{19}$

\section{CONCLUSION}

The risk of malignancy index is a simple scoring system, appears to be very accurate, is useful in clinical practice, and should therefore be the test of choice in the preoperative evaluation of the adnexal mass. . Since the specificity of risk of malignancy index is high, there is a potential role for this index in the selection of cases for conservative management or minimal invasive surgery like ultrasound guided aspiration or laparoscopic excision of other cysts. The present study demonstrates that the validity of RMI is higher as compared to validity of individual parameters and hence, has a better discriminating power to diagnose malignancy. Easy applicability of this primary evaluation makes it a good option for evaluation of pelvic masses in gynaecological practice. 


\section{ACKNOWLEDGMENTS}

Authors would like to thank Department HOD, Dr. S. M. Kalamani MD, DGO for her valuable guidance and support and sincere thanks to the Department of Pathology of present institute for their support in completing this research article.

\section{Funding: No funding sources}

Conflict of interest: None declared

Ethical approval: The study was approved by the Institutional Ethics Committee

\section{REFERENCES}

1. Gillis CR, Hole DJ, Still RM, Davis J, Kaye SB. Medical audit, cancer registration, and survival in ovarian cancer. Lancet. 1991;337:611-2.

2. Finkler NJ, Benacerraf B, Lavin PT, Wojciechowski C, Knapp RC. Comparison of serum CA-125, clinical impression, and ultrasound in the preoperative evaluation of ovarian masses. Obstet Gynecol. 1988;72:659-64.

3. Vasilev SA, Schlaerth JB, Campeau J, Morrow CP. Serum CA-125 levels in preoperative evaluation of pelvic masses. Obstet Gynecol. 1988;71:751-6.

4. Jacobs I, Oram D, Fairbanks J, Turner J, Frost C, Grudzinskas JG. A risk of malignancy index incorporating CA-125, ultrasound and menopausal status for the accurate preoperative diagnosis of ovarian cancer. Br J Obstet Gynecol. 1990;97:922-9.

5. Tingulstad S, Hagen B, Skjeldestad FE, Onsrud M, Kiserud T, Halvorsen T, et al. Evaluation of a risk of malignancy index based on serum CA-125, ultrasound findings and menopausal status in the preoperative diagnosis of pelvic masses. $\mathrm{Br} \mathrm{J}$ Obstet Gynaecol. 1996;103:826-31.

6. Tingulstad S, Hagen B, Skjeldestad FE, Halvorsen T, Nustad K, Onsrud M. The risk-of-malignancy index to evaluate potential ovarian cancers in local hospitals. Obstet Gynecol. 1999;93:448-52.

7. RCOG Guideline No. 34 October 2003, Reviewed 2010.

8. Hartge P, Hayes R, Reding D, Sherman ME, Prorok $\mathrm{P}$, Schiffman $\mathrm{M}$, et al. Complex ovarian cysts in postmenopausal women are not associated with ovarian cancer risk factors: preliminary data from the prostate, lung, colon, and ovarian cancer screening trial. Am J Obstet Gynecol. 2000;183:1232.

9. Barber HR, Graber EA. The PMPO syndrome (postmenopausal palpable ovary syndrome). Obstet Gynecol. 1971;38:921-3.

10. Aktürk E, Karaca RE, Alanbay İ, Dede M, Karaşahin $\mathrm{E}$, Yenen $\mathrm{MC}$, et al. Comparison of four malignancy risk indices in the detection of malignant ovarian masses. J Gynecol Oncol. 2011;22(3):177-82.
11. Yamamoto Y, Yamada R, Oguri H, Maeda N, Fukaya T. Comparison of four malignancy risk indices in the preoperative evaluation of patients with pelvic masses. Europ J Obstet Gynecol Reprod Biol. 2009;144(2):163-7.

12. Hartman CA, Juliato CR, Sarian LO, Toledo MC, Jales RM, Morais SS, et al. Ultrasound criteria and CA 125 as predictive variables of ovarian cancer in women with adnexal tumors. Ultrasound Obstet Gynecol. 2012;40(3):360-6.

13. Bouzari Z, Yazdani S, Ahmadi MH, Barat S, Kelagar $\mathrm{ZS}$, Kutenaie MJ, et al. Comparison of three malignancy risk indices and CA-125 in the preoperative evaluation of patients with pelvic masses. BMC Res Notes. 2011;4:206.

14. Kestane I, Senol T, Kahramanoglu I, Kestane D. The use of risk of malignancy index for adnexal masses. Gynecol Obstet. 2014;4:226.

15. Kabawat SE, Bast RC, Welch WR, Knapp RC, Calvin RB. Immunopathologic characterization of a monoclonal antibody that recognizes common surface antigens of human ovarian tumours of serous, endometrioid and dear cell types. Am J Clin Pathol. 1983;79:98-104.

16. Anton C, Carvalho FM, Oliveira EI, Maciel GAR, Baracat EC, Carvalho JP. A comparison of CA125, HE4, risk ovarian malignancy algorithm (ROMA), and risk malignancy index (RMI) for the classification of ovarian masses. Clinics. 2012;67(5):437-41.

17. Karimi-Zarchi M, Mojaver SP, Rouhi M, Hekmatimoghaddam SH, Moghaddam RN, YazdianAnari P, et al. Diagnostic value of the risk of malignancy index (RMI) for detection of pelvic malignancies compared with pathology. Electronic Physic. 2015;7(7):1505.

18. Varras M. Benefits and limitations of ultrasonographic evaluation of uterine adnexal lesions in early detection of ovarian cancer. Clin Exp Obstet Gynecol. 2003;31(2):85-98.

19. Yelikar KA, Deshpande SS, Nanaware SS, Pagare SB. Evaluation of the validity of risk malignancy index in clinically diagnosed ovarian masses and to compare it with the validity of individual constituent parameter of risk malignancy index. Int J Reprod Contracept Obstet Gynecol. 2016;5(2):460-4.

Cite this article as: Jenitha B, Subbiah M.

Diagnostic value of risk malignancy index (RMI) for detection of malignancies in clinically diagnosed ovarian masses and to evaluate the validity of individual constituent parameter of risk malignancy index. Int J Reprod Contracept Obstet Gynecol 2019;8:1558-62. 